\title{
Design of Monolithic Integrator for Strain-to-Frequency Converter
}

\author{
Tuan Mohd. Khairi Tuan Mat ${ }^{1}$, Chew Sue Ping ${ }^{2}$, Akram Abdul Azid ${ }^{3}$ \\ Faculty of Engineering, National Defence University of Malaysia, Kem Sungai Besi, 57000 Kuala Lumpur, Malaysia \\ E-mail: ${ }^{1}$ ramd87@yahoo.com, ${ }^{2}$ sueping@upnm.edu.my, ${ }^{3}$ akram@upnm.edu.my
}

\begin{abstract}
Strain-to-Frequency converter (SFC) is a one of the analog conditioner tools that converts any strain signal to the frequency signal. The basic concept of SFC is by detecting any changing of strains, then converting the strain to the voltage signal and converting the voltage signal to the frequency signal. This tool consists of 3 main components which are strain gauge, differential integrator and comparator. This paper presents the designing and analysis of monolithic integrator that to be used in the Strain-toFrequency converter. The primary goal is to design and simulate the performance of monolithic integrator for SFC using GATEWAY Silvaco Electronic Design Automation (S EDA) tools and EXPERT software. The performances of SFC using the designed monolithic integrator are also investigated.
\end{abstract}

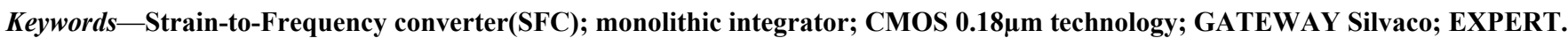

\section{INTRODUCTION}

In SFC systems, one of key issues is designing of compact integrated circuit while providing high accuracy measurement. This paper presents the design of a compact monolithic integrator using the CMOS $0.18 \mu \mathrm{m}$ technology that to be implemented in SFC circuit. The circuit will be designed and simulated using GATEWAY software. Operational amplifier will be designed and analyzed first in order to obtain stable working condition. A few equations are used in determining the sizing of transistor for op amp stability [1].

$$
\begin{gathered}
\mathrm{GB}=\mathrm{gm}_{2} / \mathrm{Cc} \\
\mathrm{Cc} \geq 0.22 \mathrm{C}_{\mathrm{L}} \\
\mathrm{gm}_{2}=\sqrt{2} \beta_{2} \mathrm{I}_{2} \\
\beta_{2}=K^{\prime} \mathrm{n}_{2}(\mathrm{~W} / \mathrm{L})
\end{gathered}
$$

The designing and simulation process are continued for the integrator, strain gauge and comparator. A few expected values for the simulation will be setup first in achieving the accurate output result. After designing of all the components, each designed components will be combined in a complete Strain-to-frequency circuit. The SFC circuit will be simulated again in order to get the accurate output result as expected. Final step is designing the layout of monolithic integrator. The layout of monolithic integrator that was designed in GATEWAY will be drawn and checked using EXPERT software.

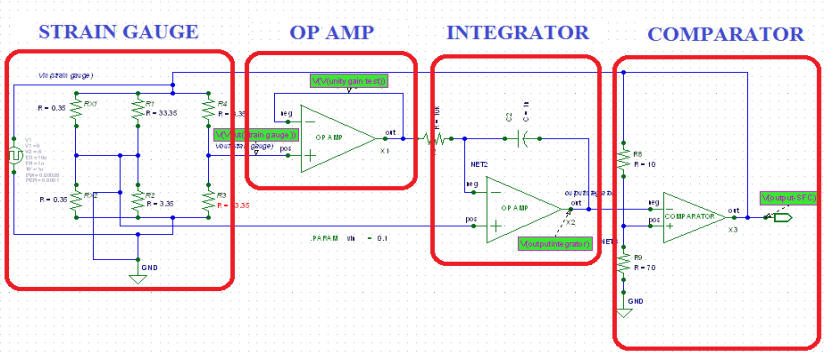

Fig. 1 Schematic of SFC

\section{RESUlts AND DISCUSSION}

The project consists of two major processes which are sketching the schematic of SFC and drawing the layout of monolithic integrator. The op amp is designed based on the specification. Table 1 shows the general critical parameter specifications for basic op amp.

To achieve all specified parameters, the circuit is analyzed using AC and transient analysis. Integrator will be designed using the designed op amp. The RC circuit with $1 \mu \mathrm{F}$ capacitor and $1 \mathrm{M} \Omega$ resistor will be applied to the op amp. The signal output will be analyzed in the wide range For the Strain Gauge, the value of the output will be simulated to enof frequency to ensure the output met the expected value.

For less critical applications, an op amp without negative feedback (open loop) is often used as a comparator [2]. In general, comparator cannot be used as op amp, but op amp 
can be used as comparator in noncritical applications. Finally, the layout of the monolithic integrator is drawn using EXPERT software. The sketched schematic of op amp in GATEWAY will be linked to EXPERT software to ensure the accuracy of design.

TABLE I

SPECIFICATIONS FOR BASIC OP-AMP

\begin{tabular}{|l|l|}
\hline Specifications & Design Requirement \\
\hline Phase Margin & $>60^{\circ}$ \\
\hline Unity Gain Frequency & $>5 \mathrm{MHz}$ \\
\hline DC Gain & $>100(40 \mathrm{~dB})$ \\
\hline Voltage Swings & $1.0 \mathrm{~V}$ to $4.0 \mathrm{~V}$ \\
\hline Slew Rate & $>5 \mathrm{~V} / \mu \mathrm{s}$ \\
\hline
\end{tabular}

\section{A. Design of $O p$ - Amp}

As very high gain bandwidth product will make the op amp to be unstable [3]. The value of width and length has been adjusted to control the amount of current in a transistor in making more stability of op amp. Table 2 shows the simulation results for the op amp and clearly shows that the op-amp has met the specifications.

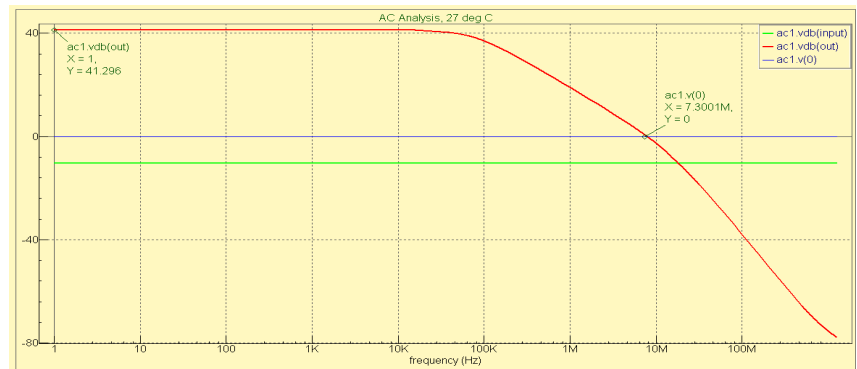

Fig. $2 \mathrm{AC}$ analysis

TABLE 2

THE OP-AMP SIMULATION RESULT

\begin{tabular}{|l|c|c|}
\hline Specifications & Expected & Results \\
\hline Phase Margin & $60^{\circ}$ & $89^{\circ}$ \\
\hline Unity Gain Frequency & $5 \mathrm{MHz}$ & $7.3 \mathrm{MHz}$ \\
\hline DC Gain & $\begin{array}{c}100 \\
(40 \mathrm{~dB})\end{array}$ & $\begin{array}{c}116.1 \\
(41.296 \mathrm{~dB})\end{array}$ \\
\hline Slew Rate & $5 \mathrm{~V} / \mu \mathrm{s}$ & $13.91 \mathrm{~V} / \mu \mathrm{s}$ \\
\hline
\end{tabular}

\section{B. Design and Simulation of Integrator}

As the capacitor charges or discharges, a current flow through capacitor is totally restricted by the internal resistance of the capacitor. This internal resistance is known as capacitive reactance which varies with frequency. As the frequency applied to the capacitor increases the reactance decreases and vice versa [4].

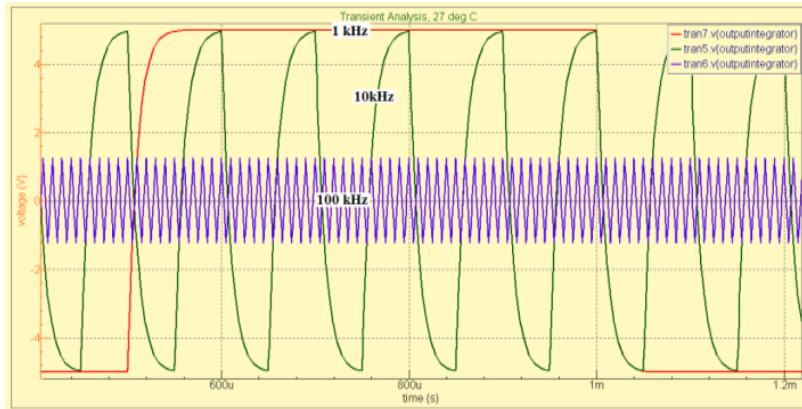

Fig. 3 Combination output of integrator

\section{Design and simulation of Strain Gauge}

The circuit in simulation result is happening after $3 \Omega$ fractional of strain occurs.

The output is $4.5843 \mathrm{~V}$ and met the targeted value, thus this schematic will be used in SFC schematic later.

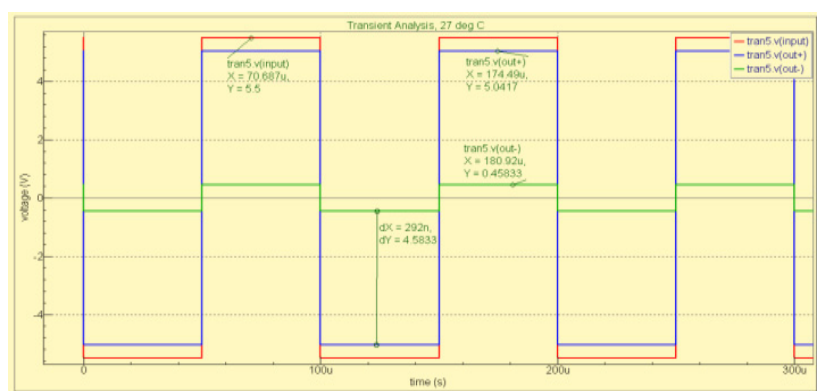

Fig. 4 Output of strain gauge

\section{Design and simulation of Comparator}

When the output is at the maximum positive voltage and the input exceeds UTP (upper trigger point), the output holds about 10 microseconds and switches to the maximum negative voltage. When the output is at the maximum negative voltage and the input exceeds LTP (lower trigger point), the output holds about 10 microseconds and switches to the maximum positive voltage. The holding output at 10 microseconds is caused by input signal frequency complete the circle at 20 microseconds for complementary input step cycle.

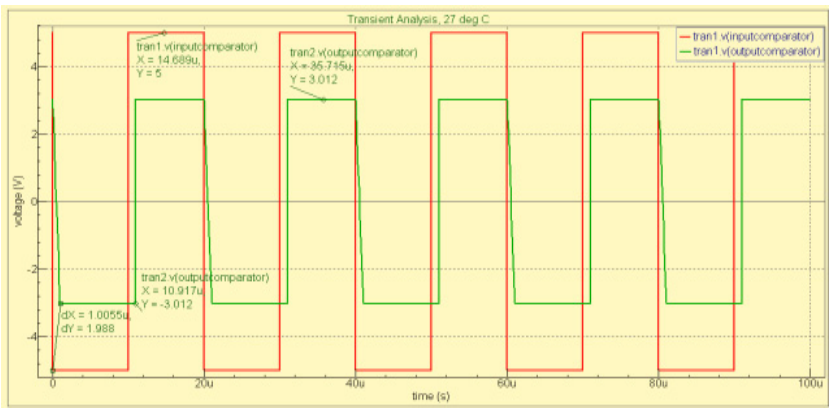

Fig. 5 Output of comparator

\section{E. Design and simulation of SFC}

The source of strain gauge is $3.5 \mathrm{~V}$ and producing $2.9 \mathrm{~V}$ out of balance from the bridge resistor. The output of integrator is $3.7 \mathrm{~V}$ while the output of SFC is $2.18 \mathrm{~V}$. To calculate the frequency, consider the circuit is starting at time is zero. If fractional occurs in strain gauge, the out of 
balance is produced and become input for voltage divider at comparator stage. At time is zero, there is no output from the integrator, but there are output from comparator. The frequency of SFC is $50 \mathrm{kHz}$.

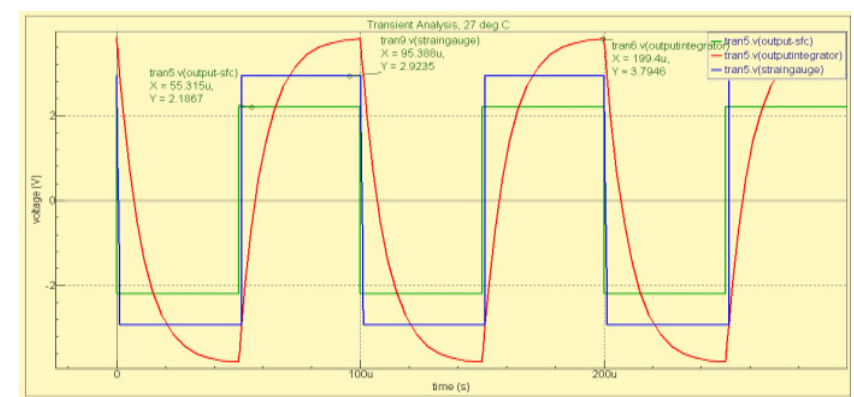

Fig. 6: Output of SFC simulation

\section{F. Layout of monolithic integrator}

The layoutof integrators consists of 5 NMOSs, 3 PMOSs, 2 capacitors and a resitor meanwhile the layout of op-amp has 9 transistors and a compensator. The negative input is connected to the resistor and capacitor. The capacitor is connected in feedback of output of integrator. The positive input is grounded to the ground. The complete layout of monolithic integrator as shown in Fig. 7 is drawn with size of $42 \mu \mathrm{m}$ length and $25 \mu \mathrm{m}$ width.

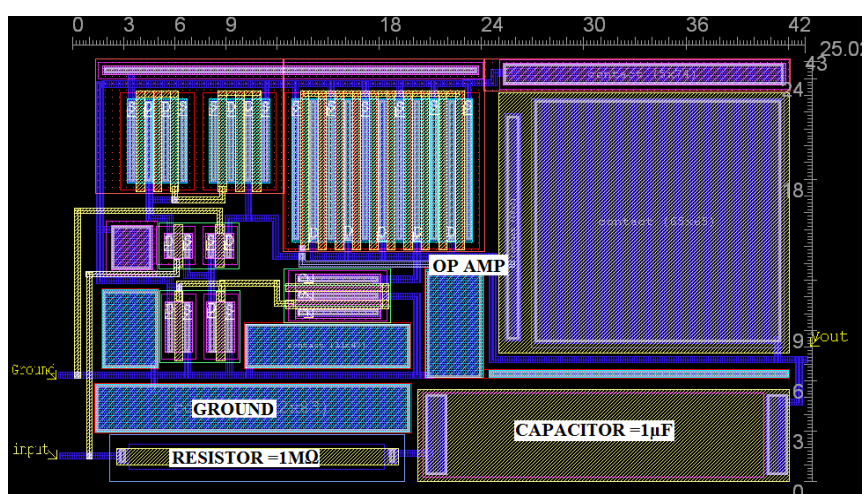

Fig. 7: Monolithic Integrator layout

\section{CONCLUSIONS}

The layout of the compact monolithic integrator is produced using EXPERT with the size is $1.05 \mathrm{~mm}^{2}$.This layout which comprises op- amp, $1 \mathrm{uF}$ capacitor and also $1 \mathrm{M} \Omega$ resistor is verified using DRC and LVS. Based on the results obatained, the simulation output is met the targeted specifications as the high slew op-amp to produce more stable operation.

\section{REFERENCES}

[1] M.H smith, L. W. (n.d.). (1999).A METHOD FOR SIZING TRANSISTOR IN CMOS OP AMP.Retrieved on Oct 28, 2010, from IEEE:http://ieeexplore.ieee.org/xpl/freeabs all.jsp?arnumber=176061

[2] Sepke, T.Holloway, P. Sodini (2009).Noise Analysis for Comparator-Based Circuits. Retrieved on Feb09, 2011, from IEEE: http://ieeexplore.ieee.org/search/freesrchabstract.jsp?tp=\&arnumber= 4588350

[3] Edward Lau, n. W. (2004). Single-Ende 2-Stage Op amp.Retrieved on October 20, 2010, from IEEE:

http://ieeexplore.ieee.org/xpl/mostRecentIssue.jsp?punumber $=555$

[4] Baschirotto, A.(2002).Considerations for the design of switchedcapacitor circuits using precise-gain operational amplifiers. Retrieved on Mac23, 2010, from IEEE:

$\mathrm{http} / / /$ ieeexplore.ieee.org/search/freesrchabstract.jsp?tp=\&arnumber= 553398 